\title{
Kalça artroskopisi: Haseki deneyimi
}

\author{
İbrahim Kaya ${ }^{1}$, Akın Uğraş², İbrahim Sungur ${ }^{1}$, Murat Yılmaz1 ${ }^{1}$ Erhan Bayram , Ahmet Ertürk1, Ercan Çetinus ${ }^{1}$
}

\begin{abstract}
ÖZET:
Kalça artroskopisi: Haseki deneyimi

Amaç: Anatomik olarak derin yerleşimli ve rijit olan kalça eklemi ve çevresinin patolojilerinin tanısı ve tedavisinde kalça artroskopisinin yeri irdelendi ve klinik tecrübelerimiz paylaşıldı.

Gereç ve Yöntem: 2011 ve 2012 yılları arasında kliniğimize aksama ve kasıkta ağrı nedeni ile başvuran kalça artroskopisi yapılan hastalar değerlendirildi. Ortalama yaş 35.8 (alt-üst sınır: 17-58)yıl olan olguların üçü bayan, 12'si erkek 15 olgu değerlendirildi. Olguların ameliyat öncesi ve sonrası Harris kalça skoruna bakıldı.

Bulgular: Olguların ortalama Harris kalça skoru ameliyat öncesi 62.7 (54-86) iken, ameliyat sonrası 92.5 (82-100) olarak saptandı. Üç hastamızda CAM tipi sıkışma saptanıp traşlandı, beş hastada labrum yırtı̆̆ı saptanıp ikisi dikildi, diğerleri debride edildi. Bir hastada osteokondral lezyon(OCD) saptanıp ters mozaikoplasti yapıldı. Bir hastada lokalize femur başı avasküler nekroz saptanarak anterior mini açık mozaikoplasti yapııdı. íki hastada eklem içinden serbest cisim, bir hastada eklem içi mermi çıkarıldı. íki hastada eklem içi patoloji saptanmadı.

Sonuçlar: Kalça artroskopisi eklem içi ve çevresindeki patolojilerin tanı ve tedavisinde deneyimli ellerde yapıldığı zaman iyi sonuçlar veren minimal invaziv bir tanı ve tedavi yöntemidir. Tekniğin başarısı yüksek olmakla birlikte nörojenik komplikasyonlar açısından cerrah portal yerleşiminde dikkatli olmalı, traksiyon süresini kısa tutmaya çalışmalıdır.
\end{abstract}

Anahtar kelimeler: Kalça eklemi, artroskopi, labrum, debridman

\section{ABSTRACT:}

Hip arthroscopy: the haseki experience

Objective: Hip is a relatively rigid and deep located joint. The role of arthroscopy in diagnosis and treatment of hip and surrounding tissue pathologies has been evaluated along with our clinical experience.

Material and Method: Fifteen hip arthroscopy cases who had admitted to our clinic with antalgic limp and groin pain between 2011 and 2012 were evaluated. Mean age was 35.8 (17-58) years. Three of the patients were female and 12 were male. Preoperative and postoperative Harris hip scores were recorded.

Results: Mean preoperative Harris Hip Score of the cases was 62.7 (54-86) and mean postoperative Harris Hip score was 92.5 (82-100). In three patients CAM type femoro-acetabular impingement was diagnosed and excessive portion of the femoral neck was shaved. In five patients, labral tears were detected. Two were repaired and three were debrided. One patient was diagnosed with osteochondral lesion and treated with reverse mosaicoplasty. Localised avascular necrosis of the femoral head was diagnosed in one patient and anterior mini-open mosaicoplasty was performed. Loose bodies were excised in two patients and intraarticular bullet was extracted in one patient. In two patients, no intraarticular pathology was detected.

Conclusion: When performed by experienced surgeons, hip arthroscopy is a minimal invasive diagnostic and treatment method which has successful results in intraarticular and periarticular hip disorders. Despite the high success rate, neurologic compromise must be avoided by paying meticulous attention in portal selection and by keeping the traction time as short as possible.

Key words: Hip joint, arthroscopy, labrum, debridement

Ş.E.E.A.H. Tıp Bülteni 2013;47(2):79-82
'Haseki Eğitim ve Araştırma Hastanesi, Ortopedi ve Travmatoloji Kliniği,

İstanbul-Türkiye

2istanbul Medipol Üniversitesi, Tıp Fakültesi, Ortopedi ve Travmatoloji Kliniği,

İstanbul-Türkiye

Yazışma Adresi / Address reprint requests to: Doç. Dr. Akın Uğraş, Medipol Üniversitesi, Ortopedi ve Travmatoloji Kliniği, TEM Avrupa Otoyolu Göztepe Çıkışı No: 1 Bağcılar 34214, İstanbul-Türkiye

E-posta / E-mail:

aaugras@medipol.edu.tr

Geliş tarihi / Date of receipt:

3 Ocak 2013 / January 3, 2013

Kabul tarihi / Date of acceptance: 5 Mart 2013 / March 5, 2013

\section{GíRiş}

Kalça artroskopisi, kalın bir kas kitlesi ve kapsül içinde bulunan kalça eklemi içindeki patolojileri tanımı ve tedavisinde giderek yaygınlaşan bir cerrahi tekniktir. Illk klinik uygulama 1939 yılında Tagaki tarafından yapılmıştır (1). 1986 yılında Eriksson tarafından uygulanan traksiyon ve cerrahi teknikler tanımlanmışır (2). 
Kalça artroskopisi, gerek kalça ekleminin anatomik lokalizasyonu ve gerekse artroskopik enstrümanların eklem içi hareket sahasının kısıtlı olması nedeni ile diğer eklem artroskopilerinden daha yavaş kullanım alanı bulmuştur. Kalça anatomisinin daha iyi anlaşıması ve enstrüman tekniklerinin gelişmesi ile son 20 yıldır hızlı bir gelişim sürecine girmiştir. Direkt grafi, BT ve $M R^{\prime}$ da saptanamayan eklem içi patolojilerin tanı ve tedavisinde altın standart olmuştur (3-5). Literatürde kalça artroskopisinin en sık endikasyonu labral patolojilerken $(6,7)$ diğer endikasyonlar arasında septik artrit, eklem içi serbest fragman, kıkırdak lezyonları, ligamentum teres yaralanmaları, eklem içi kurşun, sinovit, osteokondral lezyon (OCD), snapping hip sendromudur (1,8-10). Artrodez, ileri derece femur başı avasküler nekroz (FBAVN) ve ağır derece koksartroz, protrusio asetabuli ise kontrendikasyonlardır $(1,10)$.

Bu çalışmanın amacı kalça artroskopisi kullanım alanı ve hastanemizde yaptığımız 15 olgudan oluşan tecrübelerimizi paylaşmaktır.

\section{GEREÇLER ve YÖNTEM}

2011 ve 2012 yılları arasında Haseki Eğitim ve Araştırma Hastanesi Ortopedi ve Travmatoloji kliniğine topallama, kalçada takılma hissi ve kasıkta ağrı nedeni ile başvurarak artroskopik olarak tedavi edilen 15 olgu değerlendirildi. Ortalama yaş 35.8 (1758) yıl olarak saptandı. Üç hasta kadın, 12 hasta erkekti. Ortalama takip süresi 8.4 aydı (alt-üst sınır: 3-14 ay). Altı olguda sağ, dokuz olguda sol taraf etkilenmişti. Tüm hastalarımıza direkt kalça grafisi, bilgisayarlı tomografi (BT), manyetik rezonans görüntüleme (MR), femoroasetabular sıkışma sendromu (FAi) düşünülen hastalara modifiye Dunn grafisi, false profil lateral grafisi çekildi.

Ortalama traksiyon süresi 78.5 (alt-üst sınır: 40-100) dakikaydı. Hastalar fonksiyonel olarak modifiye Haris kalça skoru ile değerlendirildi (Tablo 1).

\section{Cerrahi Teknik}

Tüm hastalar genel anestezi altında traksiyon masasına alınarak, geniş ve yumuşak bir perine desteği ile eklem 1-1.5 cm distrakte edildi. Trokanter major ve SiAS gibi anatomik belirteçler çizildikten sonra, anterolateral portal skopi altında kanüllü kılavuz iğnesi horizontal hattan 45, orta hattan 30 derecelik açı verilerek açıldı. Kanüllü dilatatörlerle eklem kapsülü genişletildi. 70 derecelik optik kullanılarak eklem görüntülendi. Aynı şekilde anterior portal benzer açı ile açıldı. İki portal arası kapsül özel artroskopi bıçağı kullanılarak birleştirildi. Bu sayede görüş alanı ve eklem içi hareket açıklığı arttırıldı. Periferik eklem artroskopi için kapsülotomi hattı ligamentum orbikülareye kadar T şeklinde genişletilir.

Traksiyon altındaki kalça ekleminin santral kısmında labrum, asetabular kıkırdak, başın yük taşıyan

Tablo 1: Hastaların tanı, tedavi, komplikasyonları ve traksiyon süreleri (FAï: Femoroasetabular sıkışma sendromu, oCD: Osteokondral defekt, OATS: osteokondral otogreft transferi, FBAVN: Femur başı avasküler nekrozu).

\begin{tabular}{|c|c|c|c|c|c|}
\hline $\mathbf{n}$ & Yaş & Tanı & Tedavi & Komplikasyon & Traksiyon süresi (dk) \\
\hline 1 & 22 & Eklem içi serbest cisim & serbest cisim çıkarılması & yok & 67 \\
\hline 2 & 43 & Labrum yırtığı & Labrum dikişi & yok & 75 \\
\hline 3 & 17 & Açıklanamayan ağrı & yok & yok & 55 \\
\hline 4 & 38 & Sol femur başı OCD & Ters OATS & Pudental palsi & 100 \\
\hline 5 & 21 & Açıklanamayan ağrı & Sinovyal biops i+debridman & yok & 52 \\
\hline 6 & 40 & Eklem içi mermi & Debridman, Mermi çıkarıldı & yok & 40 \\
\hline 7 & 44 & $\begin{array}{l}\text { Labrum yırtığı + } \\
\text { kıkırdak delaminasyonu }\end{array}$ & Labrum dikişi + Mikrokırık & Pudental palsi & 110 \\
\hline 8 & 58 & CAM tipi FAi & $\begin{array}{l}\text { Labrum debridmanı, } \\
\text { Boyun traşlandı }\end{array}$ & İdrar inkontinans & 95 \\
\hline 9 & 27 & Labrum yırtığı & Debridman & yok & 76 \\
\hline 10 & 35 & Labrum yırtığı & Debridman & yok & 60 \\
\hline 11 & 46 & Kalsifiye labrum yırtığı & Debridman & yok & 85 \\
\hline 12 & 36 & FBAVN (lokal) & Mini açık mozaikoplasti & yok & 73 \\
\hline 13 & 33 & Cam tipi FAi & Boyun traşlama & Spontan ejekülasyon & 100 \\
\hline 14 & 42 & Osteokondromatozis & $\begin{array}{l}\text { Debridman + eklem içi } \\
\text { serbest cisim çıkarılması }\end{array}$ & yok & 68 \\
\hline 15 & 35 & $\begin{array}{l}\text { Cam tipi FAI + } \\
\text { Labrum yırtığı }\end{array}$ & $\begin{array}{c}\text { Boyun traşlama }+ \\
\text { debridman }\end{array}$ & Pudental palsi & 80 \\
\hline
\end{tabular}




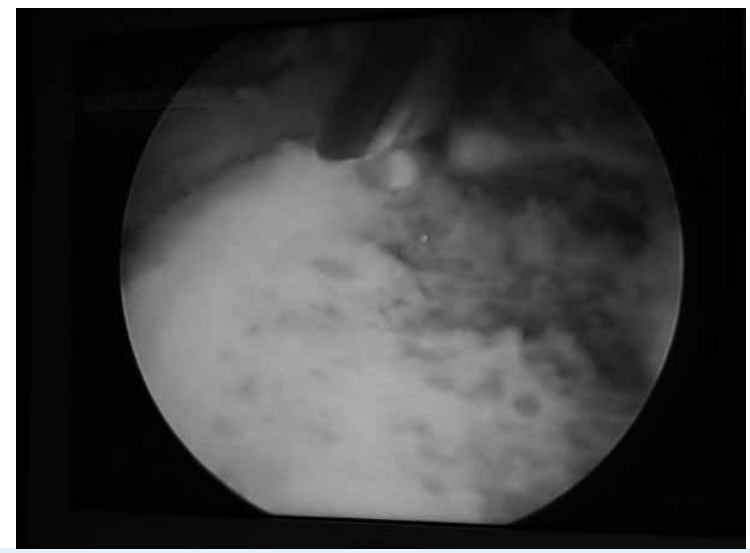

Şekil 1: CAM tipi sıkışma sendromlu olguda traşlanmış femur baş boyun bileşke tümseği

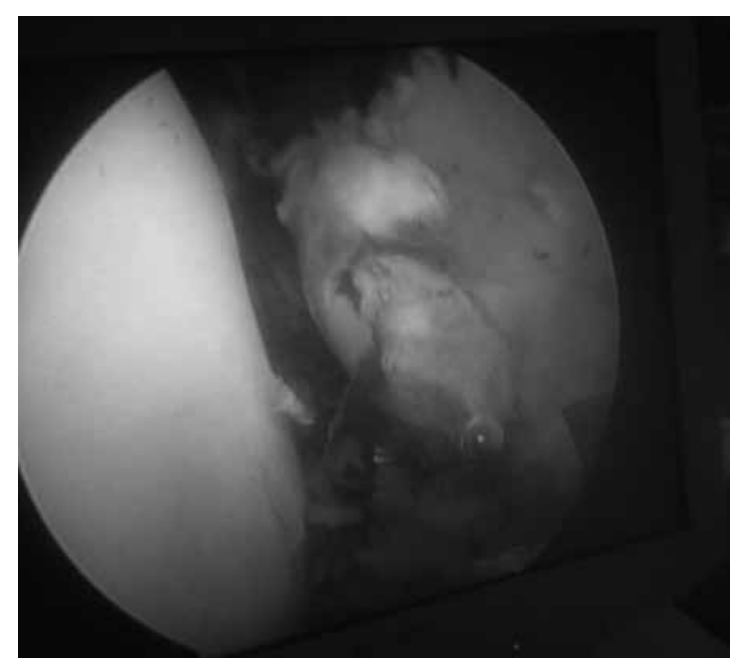

Şekil 2: Sinovyal kondromatozisli olguda eklem içi serbest cisim görüntüsü

kısmı görüntülenip, patolojilere yönelik işlemler yapıldı. Daha sonra traksiyon gevşetilip kalça fleksiyona getirilerek kalça ekleminin periferik kısmı görüntülendi. Anteriordan girilerek baş boyun bileşkesinde tespit edilen patolojiler düzeltildi.

\section{BULGULAR}

Üç hastamızda CAM tipi (mildirseği) sıkışma saptanıp traşlandı (Şekil 1), beş hastada labrum yırtığı saptanıp ikisi dikildi, diğerleri debride edildi. Bir hastada OCD saptanıp reverse-mozaikoplasti yapıldı. Bir hastada lokalize FBAVN saptandı. Anterior artrotomi ile mini-açık mozaikoplasti yapıldı. Iki hastada eklem içi serbest cisim, bir hastada eklem içi mermi

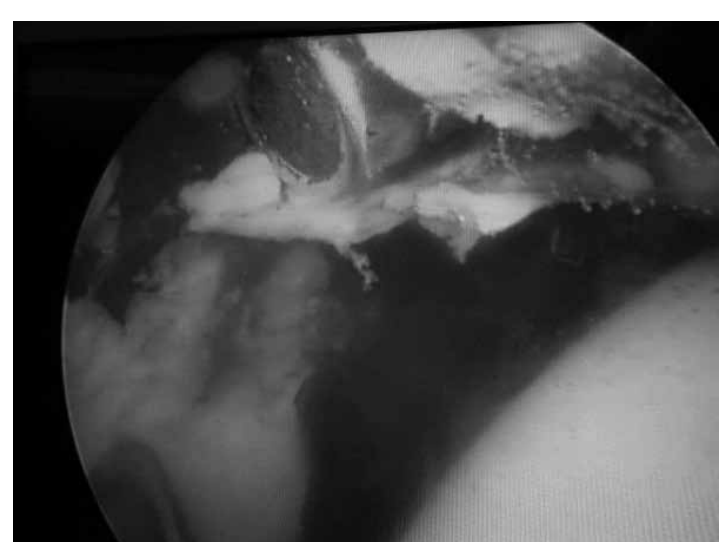

Şekil 3: Eklem içi mermi çekirdeği görünmekte

çekirdeği çıkarıldı (Şekil 2,3). İki hastada ise eklem içi patoloji saptanamadı.

Hastalarımızın ortalama Harris kalça skoru ameliyat öncesi 62.7 (54-86) iken, ameliyat sonrası 92.5 (82-100) olarak saptandı.

Beş olgumuzda perinede geçici hipoestezi, bir olguda idrarını hissetmeme ve bir olguda spontan ejekülasyon saptandı. Bütün bu pudental sinir ile ilgili nörojenik şikayetler herhangi bir müdahale yapılmadan kendiliğinden iyileşti.

\section{TARTŞMA}

Bu çalışmada hastaların ortalama Harris kalça skorunda ameliyat sonrası belirgin artış saptandı. Eklem içi serbest cisim çıkarma gibi olgularda daha yüksek puanlar elde edilirken, kondral lezyonların eşlik ettiği FAi ve labral yırtıklarda elde edilen puanlar daha düşüktü. Kalça artroskopisi endikasyonlarında önemli yer tutan labral yırtıkların çıkarılması sırasında kıkırdak lezyonu yaparak erken artroza sebep olabilir $(11,12,15,16)$. Olguların beşinde rastladığımız labrum yırtığının tanısı artro-MR ile konuldu. Labrumun kalça eklemindeki hidrostatik negatif basıncın yarısından sorumlu olduğunu ve sinovyal sıvıyı santral kompartmanda hapsettiği düşünülerek olabildiğince korumak gerekir $(13,14,17,18)$. İki olgumuza labrum yırtığını dikişle tamir edilirken diğer üç olguda debridman yapıldı.

Tüm hastalarımıza supine pozisyonda işlemler gerçekleştirildi. Özel traksiyon ekipmanı gerektiren lateral traksiyon pozisyonu da femur boyunun lataral 
kısım kapsülünün daha ince olması sebebi ile daha kolay bir giriş sağlar Ve femur boynunun anterior, lateral ve posterior kısmı daha iyi görülebilir (1).

Villar ve ark. aşırı olmayan dejeneratif kalçalarda yapılan atrtroskopik debridman ve lavajın Haris kalça skorunda \%60'lara varan iyileşme sağlandığını belirmişlerdir $(1,20)$.

Komplikasyon olarak traksiyona bağlı pudental, siyatik ve femoral sinir paralizileri görülebilirken, anterolateral portale yakınlığından dolayı kutaneal femoral sinir hasarı bildirilmiştir $(12,15)$. Clarke ve ark. 1054 kalça artroskopisinde, komplikasyon oranının \%1.4 olduğunu belirterek bunlar içinde en sık olarak nöropraksi görüldüğünü belirtmişlerdir (16). Pudental sinir palsissi en sık karşılaşılan nörolojik komplikasyondur $(6,7,17,18)$. Nörojenik komplikasyonların önlenmesinde traksiyon süresi ve perine desteği önemlidir. Traksiyon süresinin iki saatten fazla olması komplikasyon oranını arttırır (12).

Bizim seride beş olguda görülen geçici pudental sinir palsisi olgularında traksiyon süresi 90 dakikadan fazla idi. Bu komplikasyonu azaltmak için kalça eklemi ve portal anatomilerinin iyi bilinmesi, geniş ped desteği ile perine desteğinin sağlanması, 30 dakika

\section{KAYNAKLAR}

1. Asik M,Dikici F. [Kalça artroskopisi]. Acta Orthop Traumatol Turc. 1998;32:260-4.

2. Eriksson E, Arvidsson I, Arvidsson H. Diagnostic and operative arthroscopy of the hip. Orthopedics. 1986; 9(2):169-76.

3. Rath E, Tsvieli O, Levy O. Hip arthroscopy: an emerging technique and indications. Isr Med Assoc J. 2012 ;14(3):170-4.

4. Smart $L R$, Oetgen $M$, Noonan B, Medvecky $M$. Beginning hip arthroscopy: indications, positioning, portals, basic techniques, and complications. Arthroscopy. 2007; 23(12):1348-53. Epub 2007 Oct 3.

5. Ruan JW, Chen M. [Clinical application progress of hip arthroscopy]. Zhongguo Gu Shang. 2011 ;24(9):794-7.

6. Lo YP, Chan YS, Lien LC, Lee MS, Hsu KY, Shih CH. Complications of hip arthroscopy: analysis of seventy three cases. Chang Gung Med J. 2006; 29(1):86-92.

7. Kowalczuk M, Bhandari M, Farrokhyar F, Wong I, Chahal M, Neely S, Gandhi R, Ayeni OR. Complications following hip arthroscopy: a systematic review and meta-analysis. Knee Surg Sports Traumatol Arthrosc. 2012 2. [Epub ahead ofprint]

8. Lee YK, Park KS, Ha YC, Koo KH. Arthroscopic treatment for acute septic arthritis of the hip joint in adults. Knee Surg Sports Traumatol Arthrosc. 2012, 1. [Epub ahead of print]

9. Stevens MS, Legay DA, Glazebrook MA, Amirault D. The evidence for hip arthroscopy: grading the current indications. Arthroscopy. 2010;26(10):1370-83.

10. Sozen YV, Polat G, Kadioglu B, Dikici F, Ozkan K, Unay $K$. Arthroscopic bullet extraction from the hip in the lateral decubitus position. Hip Int. 2010;20(2):265-8. traksiyon yapıp arada 10 dakika traksiyonun gevşetilmesi önerilen çözümlerdir (6).

Ekleme ilk girişte yaygın olarak kullanılan anterolateral portal en güvenli portaldır. Anterior portal lateral kuteneal femoral sinire oldukça yakınken, femoral sinire ise $3.2 \mathrm{~cm}$ uzaklıktadır. Anterior ve anterolateral portallerin açılması santral ve periferik eklem lezyonlarının çoğunun tanısı ve tedavisi için yeterlidir (19).

Hastaların ameliyat sonrası rehabilitasyon programı yapılan işlemle doğrudan ilişkilidir. Ameliyat sonrası hemen aktif kalça hareketleri ve kuadriseps kas güçlendirici egzersizler verilir. Basit labrum debridmanında hemen yük verilirken asetabulum rezeksiyonundan bir hafta sonra femur boynu traşlamasından 3 hafta sonra tam yüke izin verilir. Mikrokırık gibi kıkrdak işlemlerde ve labrum tamirlerinde özellikle terminal rotasyon hareketleri için 6-8 hafta beklenmelidir (20).

Kalça artroskopisi gerek eklem içi gerek eklem çevresi patolojilerin tanısı ve tedavisi açısından öğrenme eğrisi yüksek olan mini-invazif bir cerrahi tekniktir. Tekniğin başarısı yüksek olmakla birlikte nörojenik komplikasyonlar açısından cerrah portal yerleşiminde dikkatli olmalı, traksiyon süresini kısa tutmaya çalışmalıdır.

11. Smith $C D$, Masouros $S$, Hill AM, Amis AA, Bull AM. A biomechanical basis for tears of the human acetabular labrum. Br J Sports Med. 2009; 43(8):574-8.

12. Polat G. Femoroasetabuler Sıkısma Sendromunun Cerrahi Tedavisi. Istanbul Üniversitesi İstanbul Tıp Fakültesi Ortopedi ve Travmatoloji ABD Uzmanlık tezi. İstanbul 2011.

13. Safran MR. The acetabular labrum: anatomic and functional characteristics and rationale for surgical intervention. I Am Acad Orthop Surg. 2010;18(6):338-45.

14. Mardones RM, Gonzalez C, Chen Q, Zobitz M, Kaufman $K R$, Trousdale RT. Surgical treatment of femoroacetabular impingement: evaluation of the effect of the size of the resection. J Bone Joint Surg Am. 2005;87(2):273-9.

15. Schiffman ED, McCarthy JC, Kwon JY. Ankle fracture following hip arthroscopy. Orthopedics. 2012 1;35(8):1290-2.

16. Clarke MT, Arora A, Villar RN. Hip arthroscopy: complications in 1054 cases. Clin Orthop Relat Res. 2003;(406):84-8.

17. Funke EL, Munzinger U. Complications in hip arthroscopy. Arthroscopy. 1996;12(2):156-9.

18. Villar RN. Arthroscopic debridement of the hip. JBone Joint Surg Br 1991;73:170-1 (suppl II).

19. Asık M, Kır MÇ. Kalça artroskopisi. Türkiye Klinikleri Ortopedi ve Travmatoloji Artroskopik Cerrahi Özel Sayısı 2009;2(3):52-6.

20. Larson CM, Giveans MR. Arthroscopic debridement versus refixation of the acetabular labrum associated with femoroacetabular impingement. Arthroscopy. 2009;25(4):369-76. 